\title{
The potential of atmospheric air cold plasma for control of bacterial contaminants relevant to cereal grain production
}

\author{
Agata Los \\ Technological University Dublin, agata.los@tudublin.ie \\ Dana Ziuzina \\ Technological University Dublin, dana.ziuzina@tudublin.ie \\ Daniela Boehm \\ Technological University Dublin, daniela.boehm@tudublin.ie
}

See next page for additional authors

Follow this and additional works at: https://arrow.tudublin.ie/schfsehart

Part of the Chemistry Commons, Environmental Sciences Commons, and the Food Science Commons

\section{Recommended Citation}

Agata Los, Dana Ziuzina, Daniela Boehm, Patrick J. Cullen, Paula Bourke, The potential of atmospheric air cold plasma for control of bacterial contaminants relevant to cereal grain production, Innovative Food Science \& Emerging Technologies, Volume 44, 2017, Pages 36-45, ISSN 1466-8564, DOI: 10.1016/ j.ifset.2017.08.008.

This Article is brought to you for free and open access by the School of Food Science and Environmental Health at ARROW@TU Dublin. It has been accepted for inclusion in Articles by an authorized administrator of ARROW@TU Dublin. For more information, please contact arrow.admin@tudublin.ie, aisling.coyne@tudublin.ie, gerard.connolly@tudublin.ie.

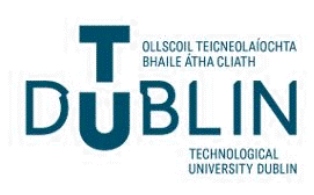




\section{Authors}

Agata Los, Dana Ziuzina, Daniela Boehm, Patrick J. Cullen, and Paula Bourke 


\title{
The potential of atmospheric air cold plasma for control of bacterial contaminants relevant to cereal grain production
}

\author{
Agata Los $^{\mathrm{a}}$, Dana Ziuzina ${ }^{\mathrm{a}}$, Daniela Boehm ${ }^{\mathrm{a}}$, Patrick J. Cullen ${ }^{\mathrm{a}, \mathrm{b}}$, Paula Bourke ${ }^{\mathrm{a}, *}$ \\ a School of Food Science and Environmental Health, Dublin Institute of Technology, Dublin 1, Ireland \\ b School of Chemical Engineering, UNSW, Sydney, Australia
}

\section{A R T I C L E I N F O}

\section{Keywords:}

Cold plasma

Bacterial biofilms

B. atrophaeus endospores

Contact angle

SEM

\begin{abstract}
A B S T R A C T
The aim of this work was to investigate the efficacy of dielectric barrier discharge atmospheric cold plasma (DBD ACP) against bacteria associated with grains quality and safety. ACP inactivation efficacy was tested against biofilms formed by different strains of $E$. coli, Bacillus and Lactobacillus in grain model media and against $B$. atrophaeus endospores either in grain media or attached on abiotic surfaces. Effects were dependent on bacterial strain, media composition and mode of ACP exposure. ACP treatment for 5 min reduced E. coli spp., B. subtilis and Lactobacillus spp. biofilms by $>3 \log _{10}$, whereas insignificant reductions were achieved for $B$. atrophaeus. ACP treatment of 5-20 min reduced B. atrophaeus spores in liquids by $>5 \log _{10}$. Treatment for 30 min reduced spores on hydrophobic surface by $>6 \log _{10}$, whereas maximum of $4.4 \log$ reductions were achieved with spores attached to hydrophilic surface. Microscopy demonstrated that ACP caused significant damage to spores. In package ACP treatment has potential to inactivate grain contaminants in the form of biofilms, as well as spores and vegetative cells.

Industrial relevance: This study demonstrates that ACP technology is a promising tool for effective bio-decontamination which offers a wide range of possible applications including inactivation of microorganisms on cereal grains. However, due to the nature of the microbial contamination of grains and complex grain structures it may be necessary to optimise the potential for surface inactivation at several stages of grain processing and storage to enhance ACP efficacy against bacterial endospores.
\end{abstract}

\section{Introduction}

Due to their worldwide significance and extensive use as human food and livestock feed, optimising the quality and safety of cereal grains and cereal products remains an important food safety issue. Microbial contamination of cereal grains derives from several sources, including air, dust, water, soil, insects, birds and rodents faeces. The main factors influencing microbial contamination and persistence on cereals are environmental conditions, such as drought, rainfall, temperature and sunlight, as well as unsanitary handling, harvesting and processing equipment, and poor storage conditions (Bullerman \& Bianchini, 2009).

The microflora of cereal grains will depend on the stage of processing and consists of moulds and bacteria. Bacteria that commonly occur on cereal grains include Pseudomonadaceae, Micrococcaceae, Lactobacillaceae and Bacillaceae (Laca, Mousia, Díaz, Webb, \& Pandiella, 2006) and they are generally non-pathogenic, however, pathogens such as Salmonella, Escherichia coli and Bacillus cereus also contaminate grains (Hocking, 2003). Although appropriate storage conditions do not promote microbial growth because of the decreased moisture content of the stored grains, a common problem of mould growth predominates on cereals, showing that these conditions are not always met (ICMSF, 1980). Some bacterial pathogens and spore-forming species can survive during storage and thus contaminate more processed products. For example, lactic acid bacteria present in the raw grain may persist through the processing and spoil doughs prepared from flour and cornmeal (Bullerman \& Bianchini, 2009; Justé et al., 2011).

Laca et al. (2006) studied the distribution of microorganisms within wheat grains and found that most of bacteria and moulds are concentrated on the surface of the grain in the pericarp surrounding the endosperm and the germ. However, some species can invade the inner part of the grains and cause internal infections. Andersen and Thrane (2006) reported that grain surface disinfection with sodium hypochlorite removed only $10-15 \%$ of Alternaria and Bipolaris, which indicated that the grains were contaminated beneath the pericarp.

As microorganisms associated with cereals are strongly adhered to the grains surface, debranning (removing the outer layers of the cereal grains) is a conventional mechanical method used to decrease cereal

\footnotetext{
* Corresponding author

E-mail address: paula.bourke@dit.ie (P. Bourke).
} 
microbial contamination (Laca et al., 2006), however, this destroys some grains. Chemical methods for sterilization may leave residues on the cereal products that may be toxic in themselves or negatively impact on subsequent grain uses. There is a need for a rapid, low energy and cost effective technology that minimises residual chemistry on the product and does not affect grain quality. An ideal method for cereals preservation should not adversely affect their quality characteristics in order to maintain high-quality processed foods with minimal changes in nutritional and sensory properties. Potential sterilization techniques include: microwave treatment (Reddy, Raghavan, Kushalappa, \& Paulitz, 1998), low-energy electrons (Röder et al., 2009), pulsed UV light (Maftei, Ramos-Villarroel, Nicolau, Mart, \& Soliva-Fortuny, 2014), organic acids (Sabillon, Stratton, Rose, \& Flores, 2016) and cold plasma treatment.

Dielectric barrier discharge (DBD) atmospheric cold plasma (ACP) has recently found an extensive range of applications in biocontrol due to the reactive oxygen species (ROS) and reactive nitrogen species (RNS) generated (Ziuzina, Han, Cullen, Keener, \& Bourke, 2015). Cold plasmas can offer a uniform non-thermal treatment and mitigate the presence of chemical residues or environmental pollutants remaining after the treatment (Dhayal, Lee, \& Park, 2006). A further advantage of cold plasma for microbial decontamination of grains is that is proven to degrade a range of pesticides that are commonly employed for cereal crops (Sarangapani et al., 2016).

The application of a new technology for food decontamination requires the evaluation of efficacy within the actual food products or in model systems that simulate food substrate composition. Therefore, to successfully apply ACP in complex food matrices such as cereal grains, primary studies in representative food model media can be employed to determine potential interactions between species generated during plasma treatment and food components. In our study, cereal-based model media were used to provide insight for the potential application of ACP for cereal grains decontamination.

The main objective of this work was to determine the efficacy of high voltage contained DBD-ACP for control of key bacteria posing grain quality and safety concerns. Different combinations of ACP treatment parameters such as mode of plasma exposure and treatment time were investigated. Thus, the efficacy against Bacillus spp., Lactobacillus spp. and E. coli, in the form of $72 \mathrm{~h}$ biofilms formed in cereal-based model media was evaluated in addition to vegetative cells and endospores suspended in liquid cereal-based media. The control of endospores attached on different types of abiotic surfaces was also examined. Contact angle measurements were conducted to characterize changes in abiotic surface properties used for bacterial inoculation as well as the surface properties of the spores attached on these surfaces post plasma treatment. The morphological changes in spores resulting from cold plasma treatment were characterized using both optical and scanning electron microscopy.

\section{Materials and methods}

\subsection{Bacterial strains and inocula preparation}

Six bacterial strains were used in this study. B. subtilis ATCC 6633, Lactobacillus plantarum ATCC 8014, Lactobacillus brevis ATCC 8287 and E. coli NCTC 12900, E. coli ATCC 25922, were obtained from the microbiology stock culture of the School of Food Science and Environmental Health of the Dublin Institute of Technology. B. atrophaeus var. niger, obtained in the form of spore strips (Sportrol ${ }^{\circledR} / \mathrm{Namsa}^{\circledR}$, VWR International, Radnor, PA, USA), was resuscitated and preserved in the form of protective beads (Technical Services Consultants Ltd., UK) inhouse. All stock cultures in the form of protective beads were maintained at $-70{ }^{\circ} \mathrm{C}$. One protective bead of culture of $E$. coli and Bacillus spp. was streaked onto separate tryptic soy agar (TSA, Biokar Diagnostics, France) plate and incubated at $37^{\circ} \mathrm{C}$ for $24 \mathrm{~h}$. Cultures of Lactobacillus spp. were streaked onto separate de Man, Rogosa and Sharpe agar (MRS agar,
Biokar Diagnostics, France) plates and incubated at $37^{\circ} \mathrm{C}$ for $48 \mathrm{~h}$. The plates were further maintained at $4{ }^{\circ} \mathrm{C}$. A single isolated colony of either E. coli or Bacillus spp. was inoculated into tryptic soy broth without glucose (TSB-G, ScharlauChemie, Spain) and incubated overnight (18 h) at $37^{\circ} \mathrm{C}$; Lactobacillus spp. was inoculated in MRS and incubated overnight at $37^{\circ} \mathrm{C}$. The bacterial density was determined by measuring absorbance at $550 \mathrm{~nm}$ using the McFarland standard (BioMerieux, Marcyl'Etoile, France) and a working inoculum corresponding to a concentration of $7.0 \log _{10} \mathrm{CFU} / \mathrm{ml}$ was prepared in either standard optimal media, model wheat or barley media, maximum recovery diluent (MRD, ScharlauChemie, Spain) or sterile deionised water. The concentration of inoculum was confirmed by plating appropriate dilutions on TSA and incubation at $37^{\circ} \mathrm{C}$ for $24 \mathrm{~h}$ for E. coli and Bacillus spp.; dilutions of Lactobacillus spp. were plated on MRS and incubated at $37^{\circ} \mathrm{C}$ for $48 \mathrm{~h}$.

\subsection{Preparation of spore suspension}

Endospores of $B$. atrophaeus were isolated according to the procedure described by Zhao, Krishna, Moudgil, and Koopman (2008) with minor modifications. Briefly, B. atrophaeus was incubated on TSA supplemented with $3.0 \mathrm{mg} / 1$ of manganese sulphate for 10 days at $30^{\circ} \mathrm{C}$. Spores were collected by flooding the agar plate with sterile PBS $(10 \mathrm{ml})$. The resulting suspension was washed twice in PBS by centrifugation at $8720 \mathrm{~g}$ for $10 \mathrm{~min}$. In order to inactivate and remove vegetative cells, bacterial suspension was heat shocked for $20 \mathrm{~min}$ at $80^{\circ} \mathrm{C}$ using a water bath, washed twice at $4{ }^{\circ} \mathrm{C}$ and finally resuspended in sterile ice cold PBS. The purity of spore suspensions was examined by using spore stain method described in Hamouda, Shih, and Baker (2002) following by optical microscopy. Spore stain method involved application of malachite green stain solution, steaming for $3 \mathrm{~min}$ and counterstaining with safranin for $30 \mathrm{~s}$. Concentration of spores was estimated by plating aliquots of the appropriate dilutions on TSA. Spore suspension was stored at $-20{ }^{\circ} \mathrm{C}$ before use.

\subsection{Preparation of wheat and barley model media}

Wheat and barley model media were prepared as for the method described by Charalampopoulos, Pandiella, and Webb (2002) with minor modifications. Either wheat or barley flour $(50 \mathrm{~g})$ was mixed with $450 \mathrm{ml}$ of tap water and centrifuged at $6000 \mathrm{~g}$ for $30 \mathrm{~min}$ at room temperature. The supernatant was sterilized at $121{ }^{\circ} \mathrm{C}$ for $45 \mathrm{~min}$. The procedures of centrifugation and sterilization were repeated four times in order to avoid the presence of sediments caused by sterilization in the final media. Prepared wheat and barley model media was stored at $4{ }^{\circ} \mathrm{C}$ before use. The $\mathrm{pH}$ value of wheat and barley media corresponded to $5.85 \pm 0.14$ and $5.25 \pm 0.12$, respectively.

\subsection{Biofilm formation}

Bacterial monoculture biofilms were formed by adding $200 \mu \mathrm{l}$ of prepared bacterial suspension of $E$. coli, Bacillus spp. and Lactobacillus spp. in either wheat or barley model medium into the wells of the 96well flat-bottomed microtiter plate (Sarstedt, Nümbrecht, Germany) and each microtiter plate contained three independently grown cultures of each bacterium. The plates were incubated at $37^{\circ} \mathrm{C}$ for $72 \mathrm{~h}$ without supernatant replacement. After incubation, the supernatant containing suspended bacterial cells was removed and the wells were washed twice with $200 \mu \mathrm{l}$ of sterile PBS, leaving only bacterial biofilms for further investigations. Biofilms were air dried for $60 \mathrm{~min}$ prior to ACP treatment.

\subsection{Inoculation procedure}

Prepared wheat and barley media, MRD and sterile deionised water were inoculated with either vegetative cells or spores of $B$. atrophaeus to a final concentration of $7.0 \log _{10} \mathrm{CFU} / \mathrm{ml}$. The resulting bacterial 


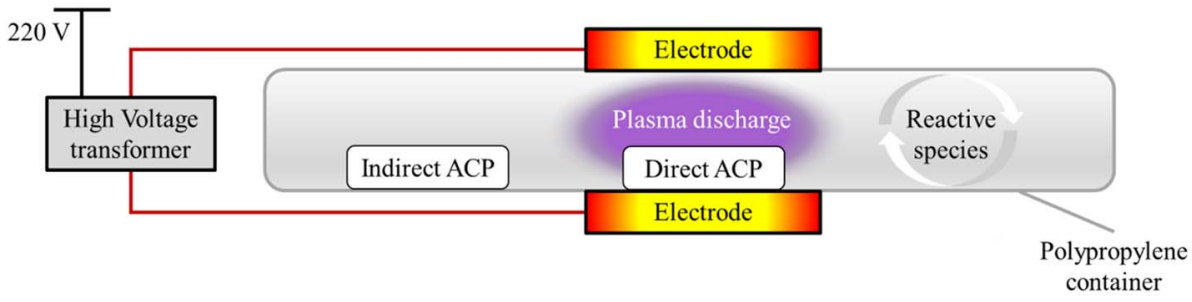

Fig. 1. Dielectric barrier discharge atmospheric cold plasma generator set-up. (Adapted from: Ziuzina, Boehm, Patil, Cullen, \& Bourke, 2015.) suspensions were further dispensed into the 96 well plate $(100 \mu \mathrm{l}$ per well) with a total volume of each media in each 96-well plate of $1.5 \mathrm{ml}$.

For abiotic surface inoculation, either synthetic butyl rubber disks (diameter $27 \mathrm{~mm}$ ), borosilicate glass slides $(76 \mathrm{~mm} \times 26 \mathrm{~mm} \times 1 \mathrm{~mm}$ ) (VWR, Ireland) or polyethylene (PE) coupons of medium porosity $(75 \mathrm{~mm} \times 25 \mathrm{~mm} \times 1.6 \mathrm{~mm}$, pore size $45-90 \mu \mathrm{m})\left(\right.$ VWR, Fritware $\left.{ }^{\circledR}\right)$ were used. The rubber disks were inoculated with $B$. atrophaeus either vegetative cell or spore suspension $(100 \mu \mathrm{l}$ per disk). The glass slides and PE coupons were inoculated only with B. atrophaeus spore suspension (100 $\mu \mathrm{l}$ per slide/coupon). Inoculated surfaces were left in the laminar flow cabinet until the inocula is completely dry.

For each ACP treatment two rubber disks inoculated with spore suspension and two rubber disks inoculated with vegetative cells were placed in sterile petri dish. In the case of other surfaces, either two glass slides or PE coupons were used for each ACP treatment.

\subsection{Experimental design}

The ACP system used (Fig. 1) in this study was a dielectric barrier discharge system with a maximum high voltage output of $120 \mathrm{kV}$ at $50 \mathrm{~Hz}$, described previously in Ziuzina, Han, et al. (2015). The distance between the two aluminium electrodes was equal to the height of the polypropylene container, used as a sample holder and a dielectric barrier, i.e. $2.2 \mathrm{~cm}$. All samples were subjected to ACP treatment at $80 \mathrm{kV}$ under atmospheric pressure. The plasma working gas was atmospheric air.

Either two microtiter plates (containing bacterial biofilms or inoculated liquids) or two petri dishes containing either rubber disks, glass slides or PE coupons were placed inside the polypropylene container. The direct and indirect plasma treatments were conducted simultaneously. For direct exposure, one microtiter plate or petri dish containing samples was placed directly between the electrodes, i.e. within the plasma discharge with $10 \mathrm{~mm}$ distance between the sample and top electrode. For indirect plasma treatment, the sample was placed in the corner of the container, the distance between the samples and the centre of the electrodes varied from 120 to $160 \mathrm{~mm}$ owing to sample distribution on the plate. Each container was sealed with a high barrier polypropylene bag (B2630; Cryovac Sealed Air Ltd., Dunkan, SC, USA) and placed between the aluminium electrodes of the transformer. The temperature increase inside the container and at the surface of the samples due to plasma treatment was $<5{ }^{\circ} \mathrm{C}$.

Before treatment the temperature of the sample surface and the temperature inside the container was at room temperature. Bacterial biofilms were exposed to direct and indirect ACP treatment for $5 \mathrm{~min}$. Bacterial vegetative cell suspensions were treated for 2, 5 and $10 \mathrm{~min}$, while 5 and 20 min of treatment was used for spores. Bacterial vegetative cells and spores inoculated on butyl rubber disks were treated for 10,20 and $30 \mathrm{~min}$; bacterial spores attached on glass slides or PE coupons were treated for $30 \mathrm{~min}$. Except for bacterial biofilms, which were assessed immediately after treatment, liquid and surface inoculated samples were stored at $15{ }^{\circ} \mathrm{C}$ for $2 \mathrm{~h}$ after treatment prior to microbiological analysis. Unless otherwise stated, all experiments were performed in duplicate and replicated at least three times. Results are expressed as logarithmic units of colony forming units per $\mathrm{ml}$ $\left(\log _{10} \mathrm{CFU} / \mathrm{ml}\right)$.

\subsection{Microbiological analysis}

Following ACP treatment, $200 \mu \mathrm{l}$ of sterile PBS was added into the wells containing biofilms and plates were sonicated using a water table sonicator (Bransonic 5510E-MT, USA, Mexico) for $10 \mathrm{~min}$. Suspensions from each well of corresponding culture were collected and vortexed in a sterile Eppendorf tube.

In order to determine the number of spores in biofilms for Bacillus spp., the suspensions were subjected to a heat-treatment $(20 \mathrm{~min}$ at $80{ }^{\circ} \mathrm{C}$ ) and cooled on ice $(10 \mathrm{~min})$ to inactivate the vegetative cells prior to enumeration.

To assess the effect of ACP treatment on bacterial cell suspensions in liquid media, corresponding samples were also collected into separate Eppendorf tubes.

To study the effect of ACP treatment on attached bacteria, the single rubber disk, glass slide or PE coupon was transferred into sterile stomacher bag containing $4 \mathrm{ml}$ of MRD. Surfaces inoculated with bacterial endospores were heat shocked for $20 \mathrm{~min}$ at $80^{\circ} \mathrm{C}$ and cooled in ice for $10 \mathrm{~min}$. Rubber disks or PE were stomached for $5 \mathrm{~min}$, while glass slides were rubbed for approximately $1 \mathrm{~min}$.

Samples were serially diluted in MRD and aliquots of appropriate dilutions, e.g. $10^{-1}, 10^{-2}$, and $10^{-3}(0.1 \mathrm{ml})$ and undiluted sample $(0.1$ and $1 \mathrm{ml}$ ) were plated on corresponding media (TSA for $E$. coli and Bacillus spp. and MRS agar for Lactobacillus spp.). Plates were incubated at $37{ }^{\circ} \mathrm{C}$ for either $24 \mathrm{~h}$ or $48 \mathrm{~h}$, respectively. Results are presented as surviving bacterial population in $\log _{10} \mathrm{CFU} / \mathrm{m} 1$ units for biofilm and liquid studies and in $\log _{10} \mathrm{CFU} /$ sample units for surface inoculation studies. The limit of detection for bacterial biofilm recovery was $2.0 \log _{10} \mathrm{CFU} / \mathrm{sample}$ (plated volume $0.01 \mathrm{ml}$ of either diluted or undiluted samples), for liquid samples was $1 \mathrm{CFU} / \mathrm{ml}$ (plated volume $1 \mathrm{ml}$ of undiluted sample) and surface inoculation studies was $4 \mathrm{CFU} /$ sample (plated volume $1 \mathrm{ml}$ of undiluted sample, i.e. suspension of cells that was detached form solid surface by transferring the samples into $4 \mathrm{ml}$ of diluent in the stomacher bag).

\subsection{Optical microscopy}

In a separate set of experiments, optical microscopy technique was used in order to visualise spore structural changes caused by either direct or indirect ACP treatment for $30 \mathrm{~min}$ and stored post treatment for $2 \mathrm{~h}$ at $15^{\circ} \mathrm{C}$. B. atrophaeus spores were inoculated on glass slides as described in Section 2.5. Either untreated or ACP treated glass slides were subjected to spore staining as described in Section 2.2. Spores were observed using light microscope (Optika, Italy) under $100 \times$ objectives (oil immersion lens, $1000 \times$ total magnification). Images were acquired with digital camera and analyzed using computer software (Optika Vision Pro).

\subsection{Contact angle measurement}

The static contact angles of deionised water (Sigma Aldrich, Ireland) were measured by sessile drop technique using contact angle meter (Theta Lite Optical Tensiometer, Biolin Scientific, UK). The surface hydrophobicity of uninoculated untreated glass slides, PE coupons and untreated glass slides was examined in addition to B. atrophaeus endospores inoculated on glass slides which were treated directly/ 
indirectly for $30 \mathrm{~min}$ with $2 \mathrm{~h}$ of post treatment storage at $15{ }^{\circ} \mathrm{C}$ was examined. Analysis was performed immediately after deposition of water droplet on the studied surfaces; the image was recorded at 15 frames per second for $10 \mathrm{~s}$. Images were analyzed using the OneAttension software.

\subsection{Scanning electron microscopy (SEM)}

The effect of ACP treatment and subsequent storage for $2 \mathrm{~h}$ at $15^{\circ} \mathrm{C}$ on $B$. atrophaeus endospores inoculated on PE coupons was analyzed by SEM. The spores attached on PE coupons were fixed in ice-cold $2.5 \%$ glutaraldehyde in $0.05 \mathrm{M}$ sodium cacodylate buffer (pH 7.4) (SCB) for $2 \mathrm{~h}$. The spores were washed with the same buffer three times and fixed in $1 \%$ osmium tetroxide for $2 \mathrm{~h}$ at $4{ }^{\circ} \mathrm{C}$. After $2 \mathrm{~h}$ of fixation, the spores were washed with SCB followed by three washes with distilled water. The samples were dehydrated using increasing concentrations of ethanol $(30 \%, 50 \%, 70 \%, 80 \%, 95 \%$ and $99.5 \%)$ following by dehydration with series of $33 \%, 50 \%, 66 \%$, and $100 \%$ of hexamethyldisilazane (Sigma Aldrich, Ireland). In order to prevent surface charging by the electron beam, the samples were sputter-coated with gold particles using Emitech K575X Sputter Coating Unit resulting in a coating of $10 \mathrm{~nm}$ after $30 \mathrm{~s}$. The samples were examined visually using a FEI Quanta 3D FEG Dual Beam SEM (FEI Ltd., Hillsboro, USA) at $5 \mathrm{kV}$.

\subsection{Statistical analysis}

Statistical analysis was performed using IBM SPSS statistics 21 Software (SPSS Inc., Chicago, USA). The surviving bacterial biofilm populations, bacteria suspended in liquids and inoculated on abiotic surfaces following ACP treatment were subjected to Mixed Design Analysis Of Variance (ANOVA). Means of ACP treated and untreated controls were compared according to the method of Fisher's Least Significant Difference-LSD at the 0.05 level.

\section{Results}

Results of this work demonstrated that intrinsic parameters such as bacterial type, strain, mode of existence, physiological state and the substrate properties significantly affected decontamination efficacy of ACP treatment.

\subsection{Effect of ACP treatment on bacterial biofilms formed in cereal model media}

The effect of the type of cereal grain model media, bacterial strain and mode of exposure on ACP treatment efficacy against bacterial biofilms was investigated (Fig. 2). Both direct and indirect ACP treatment for 5 min significantly reduced $72 \mathrm{~h}$ biofilms regardless of the media used for biofilm formation, for all the strains tested except $B$. atrophaeus. Bacterial growth within $24 \mathrm{~h}$, assessed by OD measurement as well as colony count assay, was comparable in both wheat and barley model media (data not shown), suggesting that the cereal media selected supported microbial growth equally. Higher inactivation effect was achieved for direct mode of exposure as compared to indirect, reducing the number of bacterial cells in biofilms to undetectable levels or slightly above the detection limit $\left(2.0 \log _{10} \mathrm{CFU} / \mathrm{ml}\right)$ for all of the species examined except for $B$. atrophaeus. In wheat model medium, direct ACP treatment reductions achieved were up to 3.27, 3.67, 3.44, 2.38 and $3.03 \log _{10} \mathrm{CFU} / \mathrm{ml}$ for E. coli NCTC 12900, E. coli ATCC 25920, B. subtilis, L. plantarum and L. brevis, respectively. In barley model medium, populations of the same strains were reduced up to $1.72,4.01,3.38,1.99$ and $3.07 \log _{10} \mathrm{CFU} / \mathrm{ml}$, respectively. In general, indirect treatment was the least efficient mode against bacterial biofilms, however, biofilms formed by E. coli ATCC 25920 and L. brevis were reduced to undetectable levels in both cereal-based media.

ACP treatment was strongly affected by phenotype and strain of bacteria studied. The highest resistance to treatment was observed for biofilms formed by B. atrophaeus, regardless of the media and mode of plasma exposure, with no significant reductions achieved for this strain. The percentage of spores in the total counts for B. atrophaeus biofilms before the ACP treatment constituted $92.9 \% \pm 3.1$ and $87.7 \% \pm 4.0$ in wheat and barley model medium, respectively, and for $B$. subtilis constituted $77.2 \% \pm 12.4$ and $84.7 \% \pm 4.4$ in wheat and barley model medium, respectively.

\subsection{Effect of ACP on B. atrophaeus vegetative cells and spores suspended in} liquid media or inoculated on the surface of rubber

The antibacterial efficacy of ACP treatment against bacterial vegetative cells and spores suspended in liquid media is presented in Figs. 3 and 4, respectively. Reduction achieved for $B$. atrophaeus vegetative cells for direct plasma treatment in wheat model media was 3.3, 3.4 and $5.1 \log _{10}$ cycles after 2, 5 and 10 min of treatment, respectively. Similar reduction levels of $3.2,3.3$ and $5.2 \log _{10}$ cycles were observed for barley model media. The highest inactivation levels were obtained for B. atrophaeus in distilled water. Overall, within $10 \mathrm{~min}$ of direct treatment vegetative cells of $B$. atrophaeus were reduced to undetectable levels in all media tested. In case of indirect mode of exposure, recorded plasma treatment efficacy was lower - only treatment for $10 \mathrm{~min}$ in MRD and water resulted in values below detection limits. B. atrophaeus spores showed higher resistance to plasma treatment. After $5 \mathrm{~min}$ of treatment $B$. atrophaeus spores were significantly reduced by $3.5 \log _{10}$ cycles in MRD and $6.2 \log _{10}$ cycles in distilled water for direct treatment and $2.8 \log _{10}$ cycles in distilled water for indirect treatment. Extending treatment time up to $20 \mathrm{~min}$ was necessary to significantly reduce the number of remaining spores in wheat and barley model media. Inactivation to undetectable levels was only achieved for spores in MRD, treated directly with plasma and in distilled water in both modes of exposure tested after $20 \mathrm{~min}$.

Reductions of $B$. atrophaeus vegetative cells and spores inoculated on the surface of synthetic butyl rubber discs are shown in Fig. 5. Populations of vegetative cells and spores of the control samples recovered after $2 \mathrm{~h}$ of storage at $15{ }^{\circ} \mathrm{C}$ were 4.4 and $6.4 \log _{10} \mathrm{CFU} /$ sample, respectively. After $10 \mathrm{~min}$ of ACP treatment, the number of vegetative cells was reduced by 2.8 and $2.4 \log _{10} \mathrm{CFU} /$ sample for direct and indirect mode of exposure, respectively. Vegetative cells were completely inactivated after $20 \mathrm{~min}$, regardless of the mode of exposure. Higher resistance was observed for $B$. atrophaeus spores - $10 \mathrm{~min}$ of treatment resulted in reduction of $1.6 \log _{10} \mathrm{CFU} /$ sample spores regardless of the mode of exposure. Extending the treatment time from $20 \mathrm{~min}$ to $30 \mathrm{~min}$ did not lead to further reductions of spores in case of both direct and indirect plasma exposure (up to $3.1 \log _{10} \mathrm{CFU} /$ sample).

\subsection{Effect of ACP on B. atrophaeus endospores inoculated on glass and porous polyethylene (PE) surfaces}

Fig. 6 shows the effect of $30 \mathrm{~min}$ of direct and indirect ACP treatment with subsequent storage for $2 \mathrm{~h}$ at $15^{\circ} \mathrm{C}$ on viability of $B$. atrophaeus spores inoculated on either glass slides or porous PE coupons. Regardless of the mode of exposure, higher reductions were achieved when spores were inoculated on porous PE surface, where the number of viable spores was reduced to undetectable levels $\left(\sim 6 \log _{10}\right.$ reduction). In contrast, spores inoculated on glass slides were reduced by 3.5 and $4.4 \log _{10}$ cycles after exposure to direct and indirect treatment, respectively.

The hydrophobic property of glass and PE material used for inoculation was determined by measuring water contact angles, which corresponded to $7.71^{\circ} \pm 1.11$ and $124.37^{\circ} \pm 9.05$ (Table 1 ), indicating hydrophilic and hydrophobic characteristics of tested surfaces, respectively (Fig. 7). 

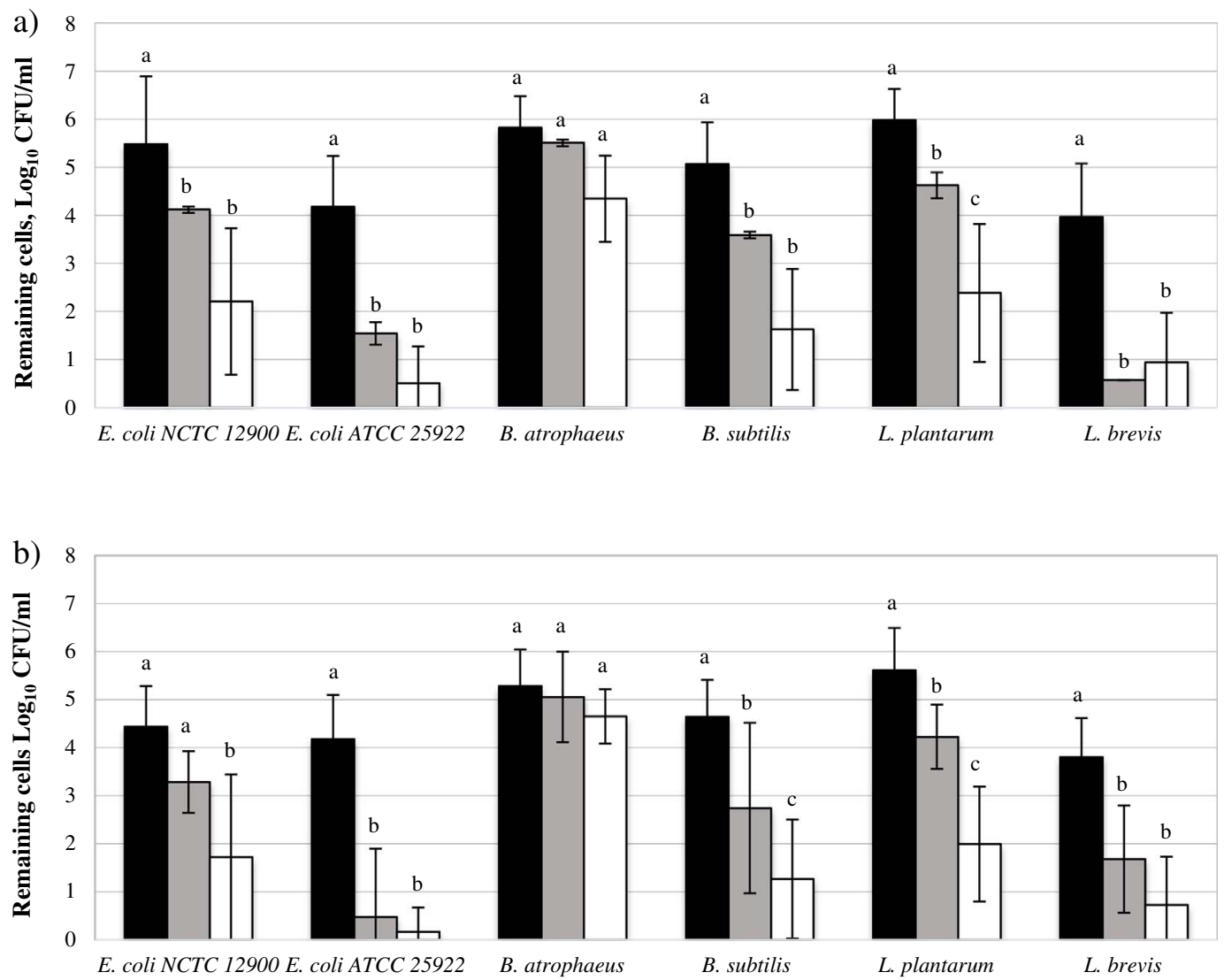

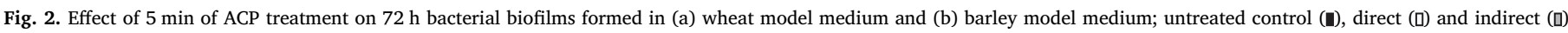

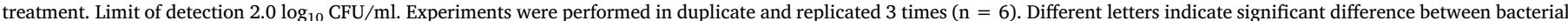
populations of the control and ACP treated samples within each type of bacteria $(\mathrm{p}<0.05)$. Vertical bars represent standard deviation.

a)

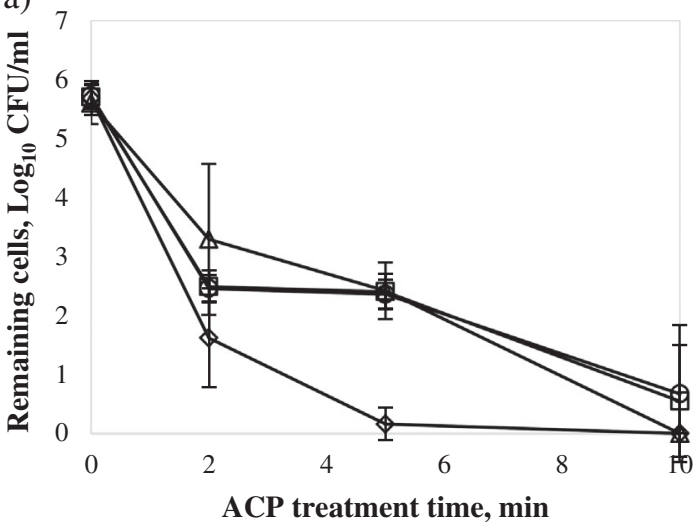

b)

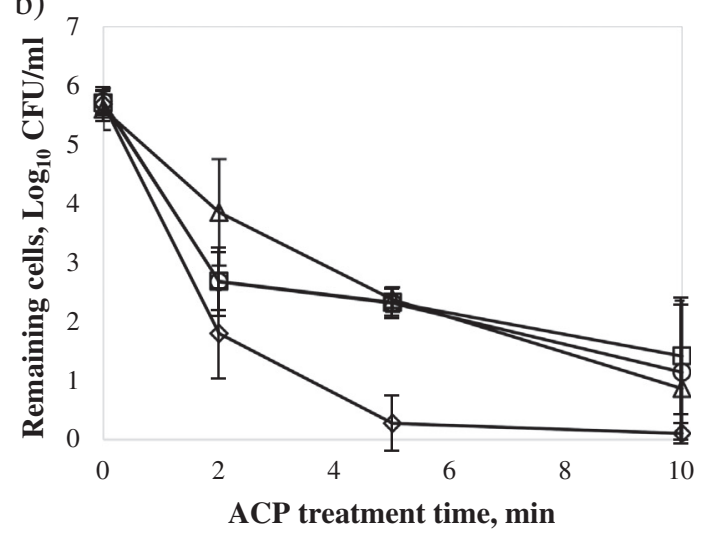

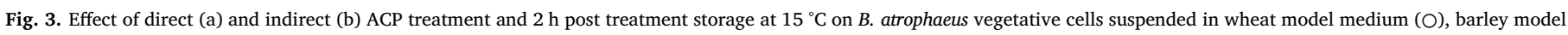

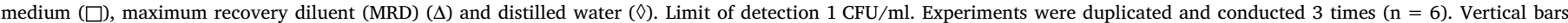
represent standard deviation.

\subsection{The effect of ACP on structural characteristics of B. atrophaeus spores}

The effect of $30 \mathrm{~min}$ of direct and indirect ACP treatment with subsequent storage for $2 \mathrm{~h}$ at $15^{\circ} \mathrm{C}$ on structural characteristics of $B$. atrophaeus spores inoculated on glass slides and porous PE surface was determined using optical microscopy (Fig. 8, top panel), water contact angles (Fig. 8, bottom panel) and SEM analysis (Fig. 9), respectively. Microscopic analysis of spores subjected to direct treatment demonstrated that most of the spores that retained structures similar to the spores of the untreated control sample (Fig. 8a) were stained green due to application of malachite green staining solution (Fig. 8b). However, spores subjected to indirect treatment were not able to retain the green dye and were counterstained in the following step involving safranin dye, thereby appearing red on the slide (Fig. 8c). Contact angle measurement also indicated the physical changes of spores following treatment (Fig. 8, bottom panel). If the water contact angle formed on the surface of spores before treatment was $7.05^{\circ} \pm 1.99$, this value increased to $27.15^{\circ} \pm 3.88$ and $39.52^{\circ} \pm 3.04$ after direct and indirect treatment, respectively (Table 1). SEM analysis confirmed physical damage of bacterial endospores inoculated on porous PE surface following treatment (Fig. 9). Unlike the micrographs of the untreated control samples (Fig. 9a), spore debris was present on the images of 
a)

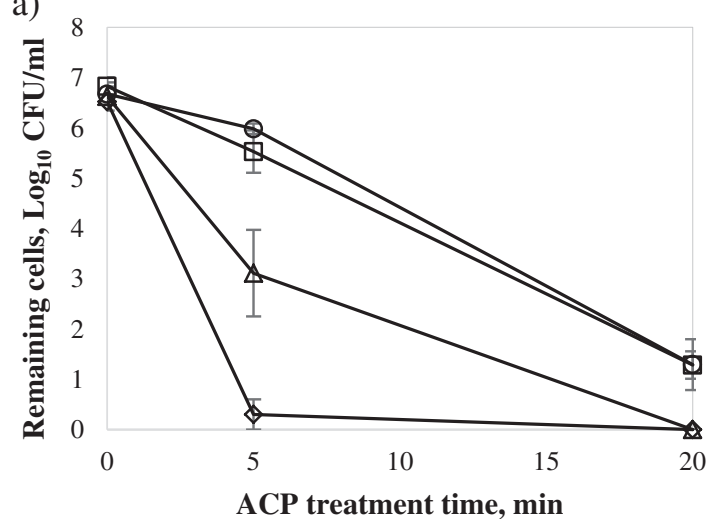

b)

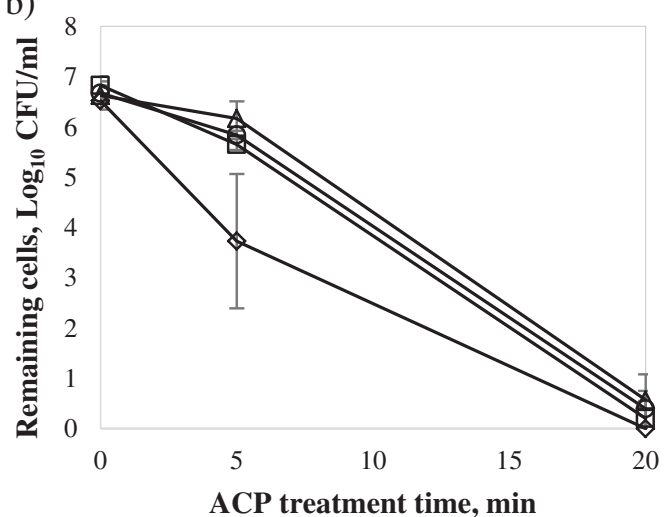

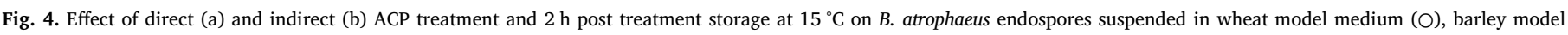

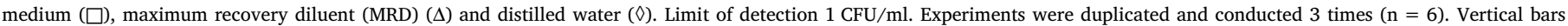
represent standard deviation.

either directly or indirectly treated samples. This indicates that ACP largely affected physical characteristics of spores through rupture and disintegration of spore structures (Fig. 9b or c, respectively).

\section{Discussion}

In summary, results of this study show that various factors including bacterial type, different physiological states of the cells and the phenotype, as well as the substrate properties play an important role in the decontamination efficacy of plasma treatment. The process parameters studied, such as treatment time and mode of plasma exposure, were also critical to achieve successful decontamination processing. Model conditions were employed to extend the findings to a range of grains.

Many human pathogens as well as spoilage microorganisms grow predominantly as biofilms, which are known to tolerate various environmental stresses and action of applied antimicrobial agents, thereby presenting a major challenge in food industry (Giaouris et al., 2013; Sharma et al., 2014). In this work high voltage DBD ACP treatment was challenged with $72 \mathrm{~h}$ biofilms of $E$. coli, Lactobacillus spp. and Bacillus spp. formed in 96 well plate model. Moreover, cereal-based liquid model media was used for biofilm formation in order to address the influence of substrate chemical composition in relation to grain industry on antimicrobial efficacy of treatment. Regardless of the type of the media selected for biofilm formation, plasma treatment for $5 \mathrm{~min}$ significantly reduced bacterial biofilms for most of the strains tested. However, the highest resistance to the treatment was observed with $B$. atrophaeus biofilm. A possible reason for the achievement of relatively low reduction levels for $B$. atrophaeus biofilms could be the induced cell sporulation during biofilm formation. Sporulation levels within biofilms depend on the incubation conditions, such as growth medium, incubation time and indeed the bacterial strain (Ramirez-Peralta et al., 2012). In this work it was experimentally determined by plate count method that the $72 \mathrm{~h}$ biofilms of $B$. atrophaeus developed in 96 well plates constituted on average of $90 \%$ of spores using either wheat or barley model media for biofilm formation, which is in accordance with previous reports. For example, Wijman, De Leeuw, Moezelaar, Zwietering, and Abee (2007) noted that percentages of spores in the total counts of $48 \mathrm{~h} \mathrm{~B}$. cereus biofilm cells constituted up to $90 \%$. Faille et al. (2014) also showed that Bacillus spp. biofilms may contain up to $90 \%$ spores after $48 \mathrm{~h}$ of incubation. Based on these results B. atrophaeus was a target microorganism for further investigations. Moreover, because previous studies reported that extending the post treatment storage time enhances bactericidal action of ACP treatment through the retention of plasma generated species in a sealed package (Ziuzina, Patil, Cullen, Keener, \& Bourke, 2013), further experiments applied a $2 \mathrm{~h}$ post treatment containment at $15{ }^{\circ} \mathrm{C}$. Thus, the influence of bacterial physiological state of $B$. atrophaeus on decontamination efficacy of ACP treatment was evident in the case of treatment of inoculated liquid media as well as for inoculated dry surfaces, where vegetative cells were readily inactivated as compared with inactivation of spores in general. These results are consistent with previous reports (Muranyi, Wunderlich, \& Langowski, 2010). Moreover, interactive effects of media composition and mode of plasma exposure were also noted. For instance, B. atrophaeus vegetative cells suspended in more complex media, either cereal-based broth or MRD, were inactivated by an average of $5 \log _{10} \mathrm{CFU} / \mathrm{ml}$ after $10 \mathrm{~min}$ of treatment despite the mode of action applied, whereas similar inactivation levels were achieved after $20 \mathrm{~min}$ of treatment in the case of $B$. atrophaeus spores. This

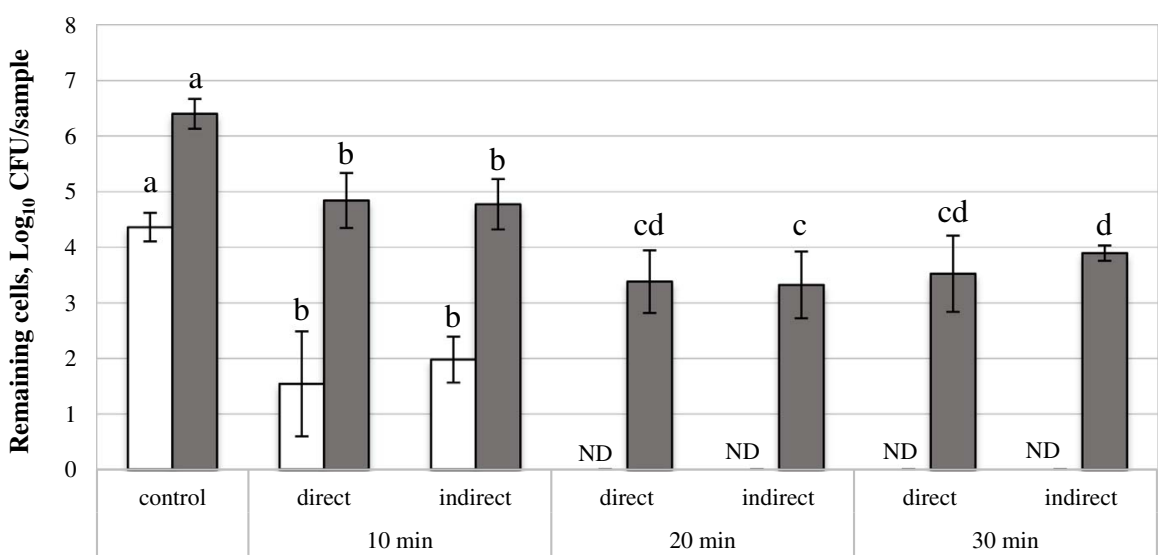

Fig. 5. Effect of direct/indirect ACP treatment and $2 \mathrm{~h}$ post treatment storage at $15{ }^{\circ} \mathrm{C}$ on B. atrophaeus vegetative cells ( $\mathrm{\square}$ ) and spores $(\square)$ on synthetic butyl rubber disks. ND - not detected. Limit of detection $4 \mathrm{CFU} /$ sample. Experiments were duplicated and conducted 4 times $(n=8)$. Different letters indicate significant difference between bacterial populations of the control and ACP treated samples within either vegetative or spore group ( $\mathrm{p}<0.05$ ). Vertical bars represent standard deviation. 


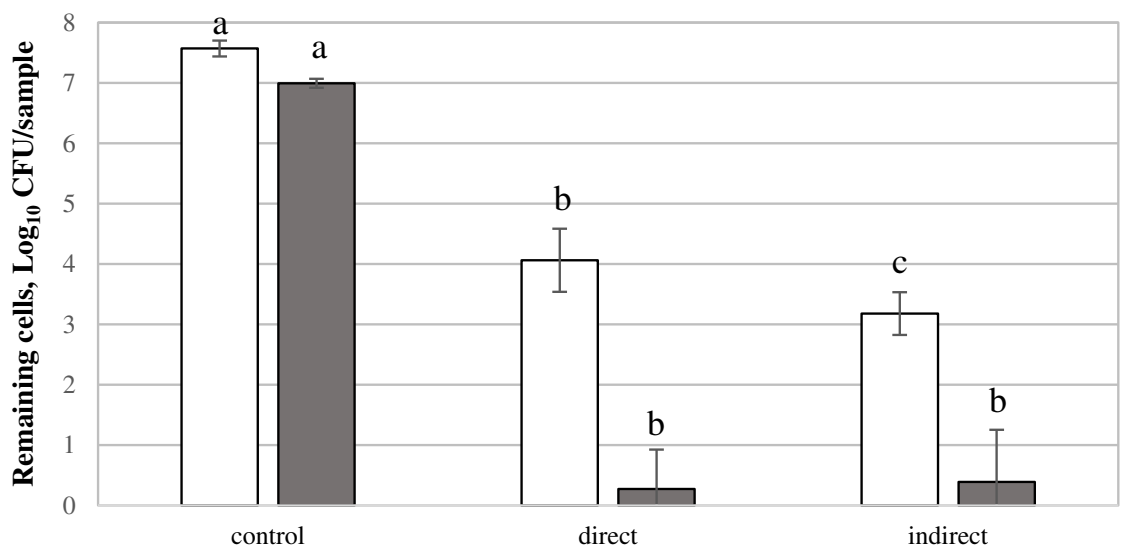

Fig. 6. Effect of direct and indirect ACP treatment of $30 \mathrm{~min}$ and $2 \mathrm{~h}$ post treatment storage at $15^{\circ} \mathrm{C}$ on $B$. atrophaeus spores inoculated on glass slides (ㅁ) and PE coupons (ㅁ). Limit of detection $4 \mathrm{CFU} /$ sample. Experiments were duplicated and conducted 4 times $(n=8)$. Different letters indicate significant difference between bacterial populations of the control and ACP treated samples within either Glass slide or PE group ( $p<0.05$ ). Vertical bars represent standard deviation.
Table 1

Water contact angle measurements on glass slide, porous polyethylene coupons and either untreated or ACP treated and stored for $2 \mathrm{~h}$ at $15{ }^{\circ} \mathrm{C}$ B. atrophaeus spores inoculated on glass slides (- untreated; \pm standard deviation). Experiments were performed in duplicate and replicated 3 times.

\begin{tabular}{lll}
\hline Surface & ACP treatment & Contact angle $^{\circ}$ \\
\hline Glass slide & - & $7.71 \pm 1.11$ \\
PE coupon & - & $124.37 \pm 9.05$ \\
B. atrophaeus & - & $7.05 \pm 1.99$ \\
B. atrophaeus & Direct & $27.15 \pm 3.88$ \\
B. atrophaeus & Indirect & $39.52 \pm 3.04$ \\
\hline
\end{tabular}

demonstrates that the complexity of nutritional environment of wheat and barley model media provided a protective effect against the action of plasma generated reactive species. Inactivation of $B$. atrophaeus vegetative cells and endospores was achieved in distilled water where 5 min of direct treatment led to undetectable levels, thus a complex medium minimises the effect of bacterial physiological state on decontamination efficacy of treatment.

Reduced inactivation efficacy of treatment was noted when either vegetative cells or spores of Bacillus were inoculated on rubber surface by comparison with liquids. Similarly, the effect of bacterial substratum on the effects of ACP was recorded in Ziuzina, Boehm, et al. (2015). Vegetative cells were not detected when an extended treatment time of $20 \mathrm{~min}$ was applied, whereas neither 20 nor $30 \mathrm{~min}$ of treatment reduced bacterial spores by $>3 \log _{10} \mathrm{CFU} /$ sample. A non-linear tailing effect for inactivation of spores could be due to the resistant nature of spores to treatment and/or limitation in the antimicrobial effects with the treatment time tested. Shintani, Sakudo, Burke, and McDonnell (2010) reports that tailing could be due to spore clumping. However, further research is needed to determine the reasons for such a response and what the optimal treatment parameters are that will be sporicidal taking factors, such as contamination levels, type of microorganisms, presence of multiculture species, cells/spores clumping, the presence of biofilms, as well as food physical and chemical characteristics to demonstrate the real potential of plasma in food processing into account. Previously we observed that relative humidity (RH) facilitated $B$. atrophaeus spores inactivation by atmospheric cold plasma (Patil et al.,
2014), where a combination of 1 min of treatment and 70\% RH resulted in $>6 \log _{10}$ reduction cycles. However, in some stages of cereal grain processing, increase in $\mathrm{RH}$ is not recommended, therefore other aspects must be taken into consideration to enhance the plasma treatment efficacy for spore inactivation on grain surfaces and in the processing environment.

In general, bacterial endospores are characterized by increased resistance to environmental stresses, including heat, radiation and common industrial processes such as pasteurization. Besides the increased resistance, other spore characteristics that make them critical for food industry include elevated adhesiveness, ability to survive for extended time and germinate after sub-lethal stress conditions (Heyndrickx, 2011; Sella, Vandenberghe, \& Soccol, 2014). Increased resistance of Bacillus endospores as compared to Bacillus vegetative cells is mainly associated with their structural complexity and chemical composition. Bacillus endospores are surrounded by a multilayered coat predominantly composed of proteins (up to $80 \%$ of total spore protein) and a minor fraction of carbohydrate components (6\%). This complex spore outer structure provides initial barrier to large molecules and has been identified as a resistance mechanism against many chemicals, particularly oxidizing agents, such as hydrogen peroxide, ozone, chlorine dioxide and hypochlorite (Sella et al., 2014). Moreover, as compared to other Bacillus spp., B. atrophaeus spores are known to be particularly resistant to ozone and plasma treatment. Under dry gaseous ozone exposure, Mahfoudh et al. (2010) showed that the inactivation rate of B. atrophaeus in comparison to spores of B. pumilus and $G$. stearothermophilus spores, was the slowest. Similarly, Klämpfl et al. (2012) observed the differences between the strains after 1 min of plasma treatment on agar plates: $B$. atrophaeus spores were reduced by approximately $2.5 \log _{10}$ cycles, while the same treatment time was sufficient for reducing the number of $B$. subtilis spores by $4.0 \log _{10}$ cycles. Therefore, we examined ACP inactivation efficacy against $B$. atrophaeus spores associated with different types of contact surfaces. For this, PE and glass material with different physical properties were selected as model systems representing both industrially relevant equipment and food surfaces with different surface topography and physical characteristics. Glass surface possesses nonporous hydrophilic features and PE has porous hydrophobic surface characteristics representing cracked grain structures and environmental a)

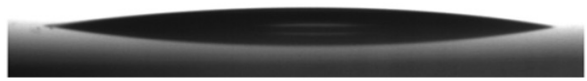

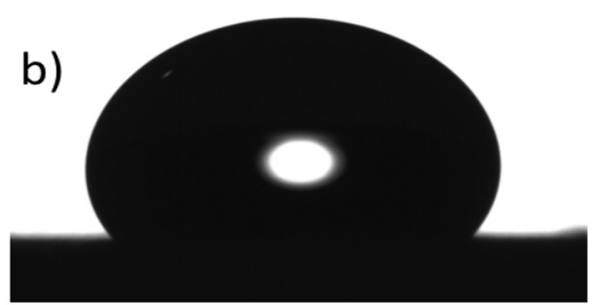

Fig. 7. Images of water droplet deposited on a) glass slide and b) polyethylene coupon. 
a)
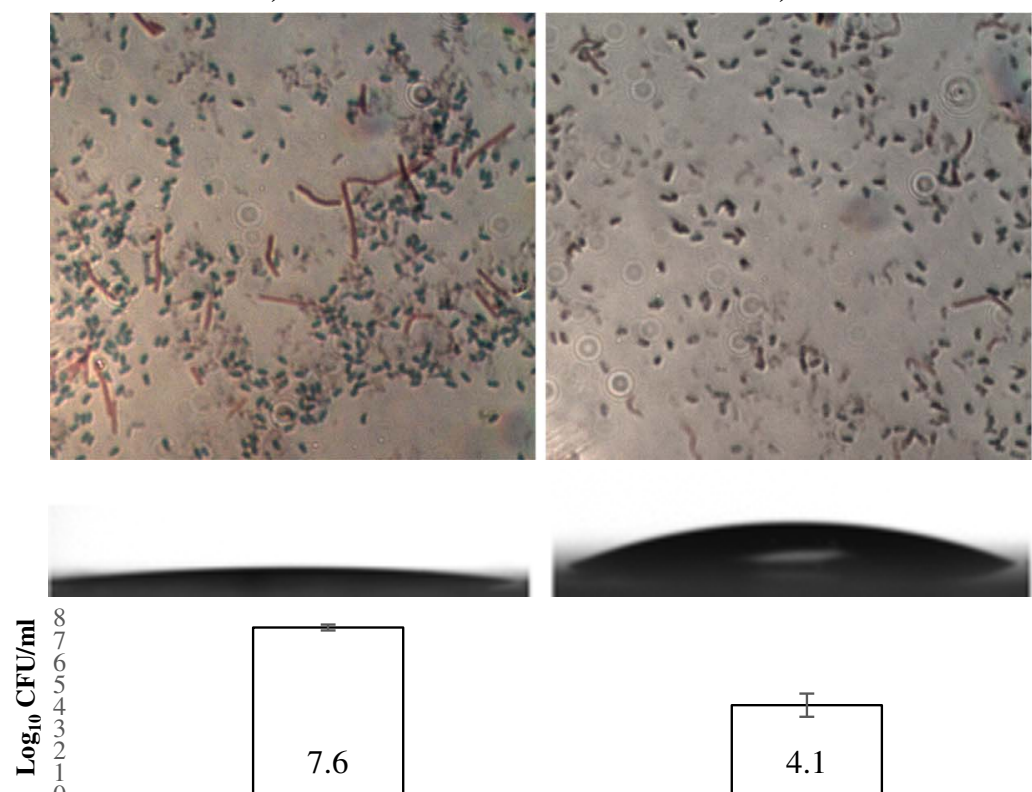

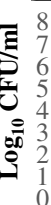
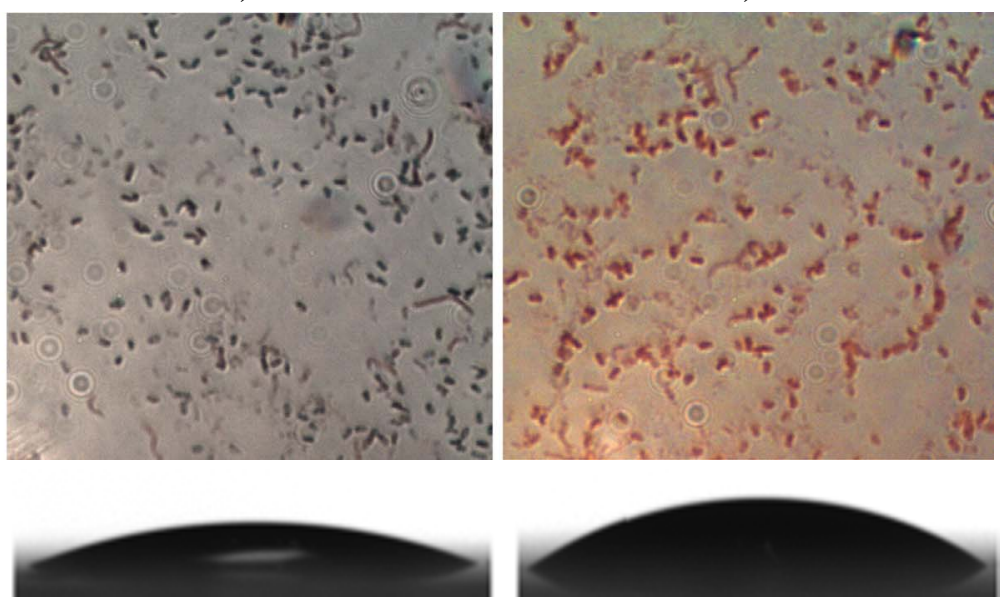

(adapted from Fig. 6)

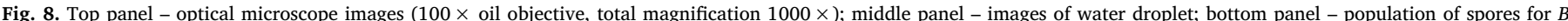
atrophaeus inoculated on glass slides a) untreated control, b) treated directly and c) indirectly for 30 min and stored post treatment for $2 \mathrm{~h}$ at $15{ }^{\circ} \mathrm{C}$.

contamination. It is widely accepted that surface roughness is one of the important factors involved in bacterial attachment and plays an important role in decontamination. Microorganisms readily attach to macroscopic crevices, pits and convolutions on inanimate and produce surface where they are protected from unfavorable environmental stresses and these features significantly alter plasma decontamination efficacy by protecting microbial cells from the action of ACP generated reactive species (Fernández, Noriega, \& Thompson, 2013; Hsu et al., 2013; Jahid, Han, Zhang, \& Ha, 2015; Ziuzina, Boehm, et al., 2015). For instance, the efficacy of atmospheric pressure DBD generated pulsed plasma treatment tested for inactivation of Geobacillus stearothermophilus was influenced by the substrate shape and surface properties. Butscher, Zimmermann, Schuppler, \& Rudolf von Rohr (2016) achieved $\sim 5 \log _{10}$ reductions within 10 min on polypropylene granules, but found that spore inactivation on wheat grains was less efficient and reached a maximum reduction of approximately $3 \log _{10}$ units after 60 min of treatment. In the current work, SEM micrographs of the inoculated PE coupons confirmed aggregation of spores within the macropores of the PE material (Fig. 9, right panel), indicating the preferential places for bacterial spore attachment. However, despite apparent irregularities and pores on the surface of PE, which could prevent direct contact of plasma generated species with spores, higher inactivation levels were obtained with porous PE substrate than with nonporous glass surface $\left(>3 \log _{10}\right.$ difference between inactivation levels). Hence, consideration of the surface porosity alone is not sufficient for the purpose of plasma processing optimization with this system. The substrate hydrophobicity was another important intrinsic parameter that played an important role in antimicrobial efficiency of ACP treatment, where enhanced plasma inactivation was associated with highly hydrophobic PE material with up to $7 \log _{10}$ reduction achieved. In general, hydrophobic materials do not support bacterial cell adhesion at the initial stages (Myszka \& Czaczyk, 2011). However, the strength of bacterial spores attachment on the surface of abiotic materials with different physical properties was not investigated in this work. Standard inoculation procedure provided only $\sim 0.5 \log _{10} \mathrm{CFU} /$ sample difference in the initial populations of spores attached on either studied surface before treatment. Moreover, SEM micrographs of untreated surface indicated the presence of high levels of spores after inoculation (Fig. 9a, right panel). A similar concentration of spores in the form of both intact and completely disintegrated spore structures were found following direct and indirect ACP treatment (Fig. 9b, c, right panel). Therefore, intrinsic factors, such as mechanism and strength of bacterial attachment, require further research to characterize plasma-spore interactions, which in turn will help in establishing efficient target-oriented microbiological control. It is also important to note, that the presence of a mixture of intact spores and spore debris as a result of relatively long treatment time (30 min) demonstrates the range of inactivation mechanisms, where multiple chemical reactions and high concentrations of reactive oxygen and nitrogen species in conjunction with plasma physical disruptive ability play a role in plasma interaction with spores. Similarly, Veen et al. (2015) reported distinct morphological changes including etching effects and the appearance of rough $B$. cereus spore surfaces observed by SEM after $20 \mathrm{~min}$ of treatment with nitrogen plasma. In the current study the occurrence of intact spores after ACP treatment as observed on SEM and low numbers of recovered spores on TSA plates indicate that ACP reactive species could possibly penetrate the spores causing major disruption at DNA levels. Muranyi et al. (2010) reported that plasma treatment could cause significant damage to the bacterial endospores genome changing the fingerprint after a treatment time of $5 \mathrm{~s}$ as demonstrated by the appearance of additional PCR products.

Furthermore, in the current study with longer treatment duration, different inactivation patterns were observed for different modes of plasma exposure examined. In the case of hydrophilic glass surface where spores exhibited higher resistance to plasma, higher reduction levels were achieved with indirect treatment $\left(4.4 \log _{10}\right)$ when compared to the reductions obtained after direct treatment $\left(3.5 \log _{10}\right)$ (Fig. 8b, c, bottom panel). The observed reductions were correlated with physical changes of spores observed through optical microscopy and contact angle measurements to determine hydrophobic characteristics of $B$. atrophaeus spores before and after treatment. The principle of spore staining with malachite green, is that the dye is forced into the spore by mild heating, which cannot be washed with water from spore structures once the dye is inside the spore. This results in green appearance of spores under the light microscope. As demonstrated on Fig. 8(b, top panel), spores that were exposed to direct treatment had 
a)
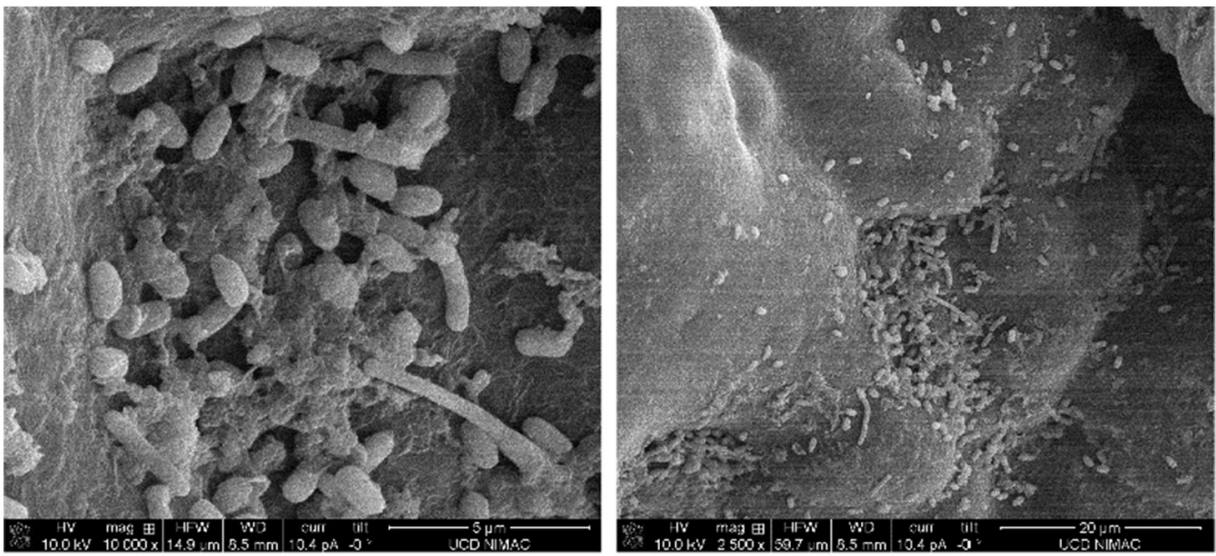

b)
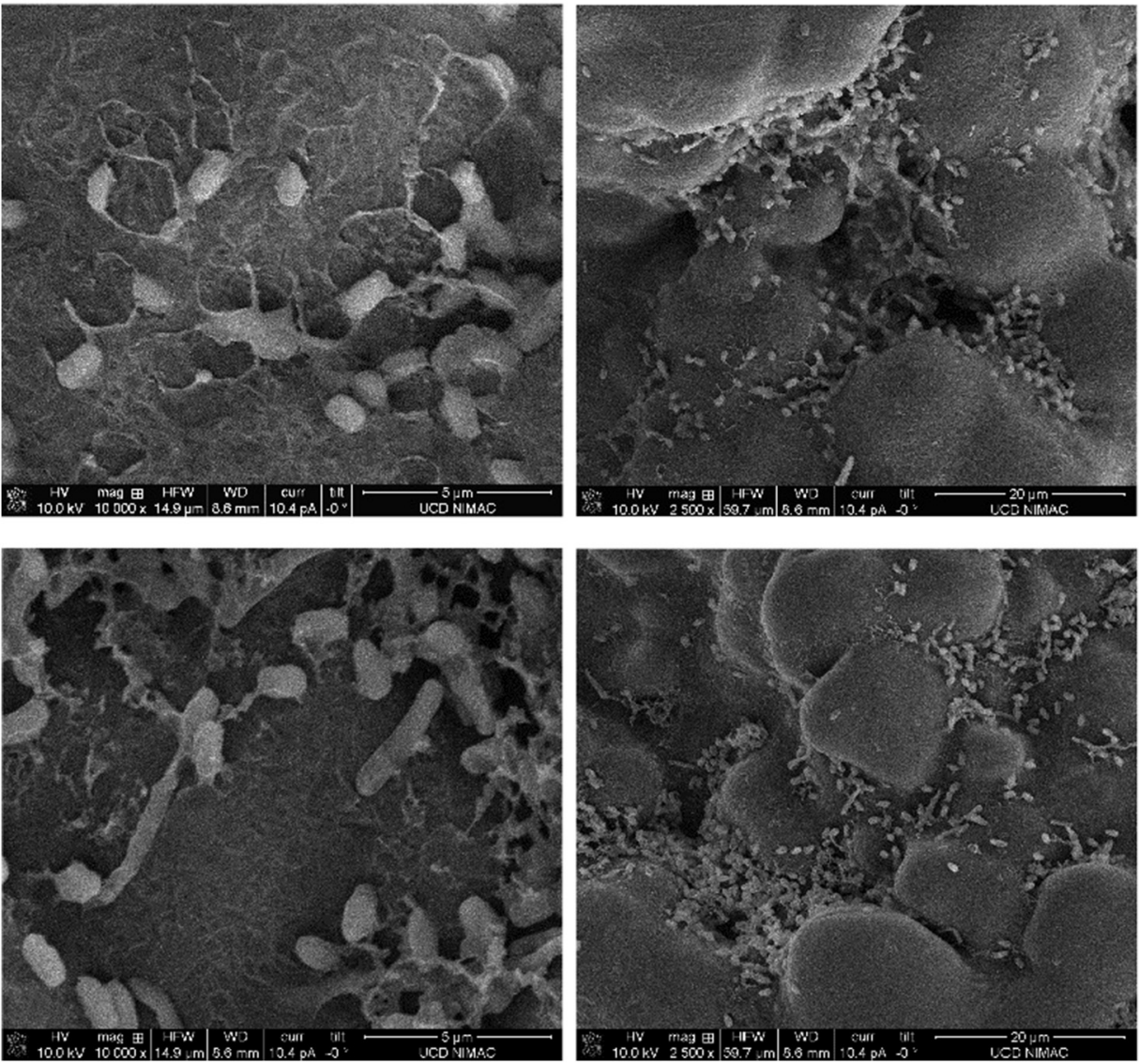

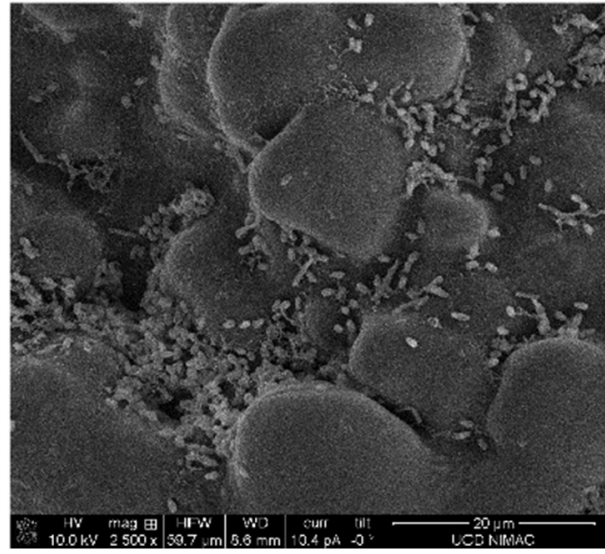

Fig. 9. SEM images of $B$. atrophaeus spores inoculated on polyethylene coupons: a) untreated control, b) treated directly and c) indirectly for $30 \mathrm{~min}$ and stored post treatment for $2 \mathrm{~h}$ at $15^{\circ} \mathrm{C}$. Magnification: left panel $10,000 \times$ and right panel $2500 \times$. the ability to retain the dye. In contrast, the green dye was easily washed off from the spores after exposure to indirect treatment and the majority of spores were stained red as a result of the application counterstain safranin (Fig. 8c, top panel). These results indicated major alterations to the spore structures caused by plasma treatment, which could affect the staining process, but also lead to lower spore recovery levels as demonstrated by plate count assay. The loss of the spores ability to retain the stain could be associated with changes in the outer pericortex region of the spores (Kozuka \& Tochikubo, 1991), however, to determine whether these changes influence the recovery of spores on TSA, a more detailed analysis of spore components responsible for the stain retention as well as for viability of spores is required. In addition, ACP treatment caused significant changes in water contact angles for bacterial spores changing hydrophilic surface of the untreated spores to more hydrophobic, which could be probably due to the local damage of proteins constituting the spore coat. Again, higher water contact angle of the spores was recorded after exposure to indirect treatment than after direct exposure. The protective mechanisms of spores in association with a range of surface and structural characteristics require elucidation for successful application of ACP technology to grain processing. Another important aspect to consider for successful application of ACP to real food systems concerns retention of physicochemical and physiological properties of grains and seeds as maximal microbial control treatment conditions may not always be associated with significant improvements in the quality. Therefore, further studies involving grain models are warranted in order to draw conclusions about possible inactivation effects and grain quality characteristics retention.

\section{Conclusion}

Overall, a significant reduction of microorganisms associated with cereal grains after ACP treatment was achieved. Results demonstrated that intrinsic parameters such as bacterial type, strain, mode of existence, substrate composition and surface hydrophobicity, as well as 
process parameters such as treatment time and mode of plasma exposure, significantly impact decontamination efficacy. Plasma treatment of 5 min was required to effectively reduce bacterial biofilms formed in grain model media for all the strains tested except for $B$. atrophaeus. Reduced inactivation efficacy of ACP treatment both in liquid cereal-based media and inoculated on rubber surface was observed for bacterial endospores as compared to vegetative cells. Enhanced plasma inactivation of $B$. atrophaeus endospores was associated with higher hydrophobicity of inoculated abiotic surface: higher reduction was achieved for hydrophobic PE coupons as compared to hydrophilic glass slides, providing insights in terms of the effect of substrate surface properties to optimise ACP processes for decontamination of cereal grains.

\section{Acknowledgements}

This work was conducted with the financial support of Science Foundation Ireland (SFI) under Grant Number 14/IA/2626.

\section{References}

Andersen, B., \& Thrane, U. (2006). Food-borne fungi in fruit and cereals and their production of mycotoxins. Adv. Exp. Med. Biol. 571, 137-152.

Bullerman, L. B., \& Bianchini, A. (2009). Food safety issues and the microbiology of cereals and cereal products. In N. Heredia, I. Wesley, \& S. Garciara (Eds.). Microbiologically safe foods (pp. 315-335). Hoboken, NJ: Wiley.

Butscher, D., Zimmermann, D., Schuppler, M., \& von Rohr Rudolf, P. (2016). Plasma inactivation of bacterial endospores on wheat grains and polymeric model substrates in a dielectric barrier discharge. Food Control, 60, 636-645.

Charalampopoulos, D., Pandiella, S. S., \& Webb, C. (2002). Growth studies of potentially probiotic lactic acid bacteria in cereal-based substrates. Journal of Applied Microbiology, 92, 851-859.

Dhayal, M., Lee, S., \& Park, S. (2006). Using low-pressure plasma for Carthamus tinctorium L. seed surface modification. Vacuum, 80, 499-506.

Faille, C., Benezech, T., Midelet-Bourdin, G., Lequette, Y., Clarisse, M., Ronse, G., .. Slomianny, C. (2014). Sporulation of Bacillus spp. within biofilms: A potential source of contamination in food processing environments. Food Microbiology, 40, 64-74.

Fernández, A., Noriega, E., \& Thompson, A. (2013). Inactivation of Salmonella enterica serovar typhimurium on fresh produce by cold atmospheric gas plasma technology. Food Microbiology, 33, 24-29.

Giaouris, E., Heir, E., Hébraud, M., Chorianopoulos, N., Langsrud, S., Møretrø, T., ... Nychas, G. J. (2013). Attachment and biofilm formation by foodborne bacteria in meat processing environments: Causes, implications, role of bacterial interactions and control by alternative novel methods. Meat Science, 97, 298-309.

Hamouda, T., Shih, A. Y., \& Baker, J. R. (2002). A rapid staining technique for the detection of the initiation of germination of bacterial spores. Letters in Applied Microbiology, 34, 86-90.

Heyndrickx, M. (2011). The importance of endospore-forming bacteria originating from soil for contamination of industrial food processing. Applied and Environmental Soil Science, 2011, 1-11.

Hocking, A. D. (2003). Microbiological facts and fictions in grain storage ochratoxin A. In E. J. Wright, M. C. Webb, \& E. Highley (Eds.). Proceedings of the Australian Postharvest Technical Conference (pp. 25-27). Canberra: CSIRO.

Hsu, L. C., et al. (2013). Effect of micro- and nanoscale topography on the adhesion of bacterial cells to solid surfaces. Applied and Environmental Microbiology, 79, 2703-2712.

International Commission of Microbiological Specification for Foods (ICMSF) (1980). Cereals and cereal products. Food commodities: . vol. 2. New York: Academic Press, Inc.

Jahid, I. K., Han, N., Zhang, C. Y., \& Ha, S. D. (2015). Mixed culture biofilms of Salmonella typhimurium and cultivable indigenous microorganisms on lettuce show enhanced resistance of their sessile cells to cold oxygen plasma. Food Microbiology, 46, 383-394.

Justé, A., Malfliet, S., Lenaerts, M., De Cooman, L., Aerts, G., Willems, K. A., \& Lievens, B.
(2011). Microflora during malting of barley: Overview and impact on malt quality. Brewing Science, 64, 22-31.

Klämpfl, T. G., Isbary, G., Shimizu, T., Li, Y.-F., Zimmermann, J. L., Stolz, W., ... Schmidt, H.-U. (2012). Cold atmospheric air plasma sterilization against spores and other microorganisms of clinical interest. Applied and Environmental Microbiology, 78(15), 5077-5082.

Kozuka, S., \& Tochikubo, K. (1991). Permeability of dormant spores of Bacillus subtilis to malachite green and crystal violet. Journal of General Microbiology, 137, 607-613.

Laca, A., Mousia, Z., Díaz, M., Webb, C., \& Pandiella, S. S. (2006). Distribution of microbial contamination within cereal grains. Journal of Food Engineering, 72, 332-338.

Maftei, N. A., Ramos-Villarroel, A. Y., Nicolau, A. I., Mart, O., \& Soliva-Fortuny, R. (2014). Pulsed light inactivation of naturally occurring moulds on wheat grain. Journal of the Science of Food and Agriculture, 94, 721-726.

Mahfoudh, A., Moisan, M., Séguin, J., Barbeau, J., Kabouzi, Y., \& Kéroack, D. (2010). Inactivation of vegetative and sporulated bacteria by dry gaseous ozone. Ozone Science and Engineering, 32, 180-198.

Muranyi, P., Wunderlich, J., \& Langowski, H. (2010). Modification of bacterial structures by a low-temperature gas plasma and influence on packaging material. Journal of Applied Microbiology, 109, 1875-1885.

Myszka, K., \& Czaczyk, K. (2011). Bacterial biofilms on food contact surfaces - a review. Polish Journal of Food and Nutrition Sciences, 61, 173-180.

Patil, S., Moiseev, T., Misra, N. N., Cullen, P. J., Mosnier, J. P., Keener, K. M., \& Bourke, P. (2014). Influence of high voltage atmospheric cold plasma process parameters and role of relative humidity on inactivation of Bacillus atrophaeus spores inside a sealed package. The Journal of Hospital Infection, 88, 162-169.

Ramirez-Peralta, A., et al. (2012). Effects of sporulation conditions on the germination and germination protein levels of Bacillus subtilis spores. Applied and Environmental Microbiology, 78, 2689-2697.

Reddy, M. V. B., Raghavan, G. S. V., Kushalappa, A. C., \& Paulitz, T. C. (1998). Effect of microwave treatment on quality of wheat seeds infected with Fusarium graminearum. Journal of Agricultural Engineering Research, 71, 113-117.

Röder, O., Jahn, M., Schröder, T., Stahl, M., Kotte, M., \& Beuermann, S. (2009). E-ventus technology - An innovative treatment method for sustainable reduction in the use of pesticides with recommendation for organic seed. Journal für Verbraucherschutz und Lebensmittelsicherheit, 4, 107-117.

Sabillon, L., Stratton, J., Rose, D. J., \& Flores, R. A. (2016). Reduction in microbial load of wheat by tempering with organic acid and saline solutions. Cereal Chemistry, 1-9.

Sarangapani, C., Misra, N. N., Milosavljevic, V., Bourke, P., O'Regan, F., \& Cullen, P. J. (2016). Pesticide degradation in water using atmospheric air cold plasma. Journal Water Process Engineering, 9, 225-232.

Sella, S. R. B. R., Vandenberghe, L. P. S., \& Soccol, C. R. (2014). Life cycle and spore resistance of spore-forming Bacillus atrophaeus. Microbiological Research, 169, 931-939.

Sharma, G., Rao, S., Bansal, A., Dang, S., Gupta, S., \& Gabrani, R. (2014). Pseudomonas aeruginosa biofilm: Potential therapeutic targets. Biologicals, 42, 1-7.

Shintani, H., Sakudo, A., Burke, P., \& McDonnell, G. (2010). Gas plasma sterilization of microorganisms and mechanisms of action (review). Experimental and Therapeutic Medicine, 1, 731-738.

Veen, H. V. B. D., et al. (2015). Inactivation of chemical and heat-resistant spores of Bacillus and Geobacillus by nitrogen cold atmospheric plasma evokes distinct changes in morphology and integrity of spores. Food Microbiology, 45, 26-33.

Wijman, J. G. E., De Leeuw, P. P. L. A., Moezelaar, R., Zwietering, M. H., \& Abee, T. (2007). Air-liquid interface biofilms of Bacillus cereus: Formation, sporulation, and dispersion. Applied and Environmental Microbiology, 73, 1481-1488.

Zhao, J., Krishna, V., Moudgil, B., \& Koopman, B. (2008). Evaluation of endospore purification methods applied to Bacillus cereus. Separation and Purification Technology, 61, 341-347.

Ziuzina, D., Boehm, D., Patil, S., Cullen, P. J., \& Bourke, P. (2015). Cold plasma inactivation of bacterial biofilms and reduction of quorum sensing regulated virulence factors cold plasma inactivation of bacterial biofilms and reduction of quorum sensing regulated virulence factors. PloS One, 10(9).

Ziuzina, D., Han, L., Cullen, P. J., Keener, K. M., \& Bourke, P. (2015). Cold plasma inactivation of internalised bacteria and biofilms for Salmonella enterica serovar typhimurium, Listeria monocytogenes and Escherichia coli. International Journal of Food Microbiology, 210, 53-61.

Ziuzina, D., Patil, S., Cullen, P. J., Keener, K. M., \& Bourke, P. (2013). Atmospheric cold plasma inactivation of Escherichia coli in liquid media inside a sealed package. Journal of Applied Microbiology, 114, 778-787. 